\title{
AS RELAÇÕES ENTRE O EXECUTIVO E O LEGISLATIVO NA ELABORAÇÃO DO ORÇAMENTO BRASILEIRO: CONSIDERAÇÕES SOBRE A EMENDA CONSTITUCIONAL 86/2015
}

\section{RELATIONS BETWEEN THE EXECUTIVE AND LEGISLATIVE POWER AT BRAZILIAN BUDGET FORMULATION: CONSIDERATIONS ABOUT CONSTITUTIONAL AMENDMENT 86/2015}

\section{Resumo}

Este artigo objetiva analisar as possíveis implicações da Emenda Constitucional 86/2015 nas relações estabelecidas entre os Poderes Executivo e Legislativo na elaboração e execução do orçamento brasileiro. Verificar-se-á a natureza autorizativa e/ou impositiva da lei orçamentária, como ocorriam as relações entre os poderes antes da EC n. 86/2015 e se e se tal alteração constitucional será capaz de mudar a dinâmica dessa relação político-institucional. Para alcançar o objetivo proposto, utilizar-se-á de fontes predominantemente teóricas, em uma abordagem compreensivo-exploratória e crítico-reflexiva sobre a matéria.

Palavras-Chave: Emenda Constitucional n. 86/2015, Orçamento, Poder Executivo, Poder Legislativo, Emendas Parlamentares.

\begin{abstract}
This article aims to analyze the possible implications of the Constitutional Amendment 86/2015 in relations between the executive and the legislative power at establishing and implementing the Brazilian budget. It will be verified the autorizing and/or the enforcing nature of the budget, how did occur such relationships before the adoption of EC n. 86/2015 and if this constitutional change will be able to cause difference in the dynamics of this political and institutional relationship. To achieve the proposed objective will be used, predominantly theoretical sources, in a comprehensive-exploratory and critical-reflexive approach on the matter.
\end{abstract}

Keywords: Constitutional Amendment n. 86/2015, Budget, Executive power, Legislative power, Parliamentary amendments.

\footnotetext{
${ }^{1}$ Doutor em Sociologia e Política, Mestre em Ciência Política, Bacharel em Direito, pesquisador e professor da Universidade Fundação Mineira de Educação e Cultura, FUMEC- MG, (Brasil).E-mail: edumlima@ fumec.br.

${ }^{2}$ Mestranda em Direito Pela Faculadade de Ciências Humanas, Sociais e da Saúde naFundação Mineira de Educação e Cultura, FUMEC - MG, (Brasil). E-mail: priscila@ priscilaviana.com.br
} 


\section{INTRODUÇÃO}

No sistema orçamentário brasileiro vigente, observa-se uma atuação de todos os poderes na elaboração das leis orçamentárias brasileiras. Contudo, cabe ao Poder Executivo a iniciativa da elaboração da lei orçamentária, que consolida as propostas parciais de todos os demais poderes em um único projeto de lei, evidenciando, assim, o seu protagonismo na definição e execução das diversas políticas públicas, bem como na gestão financeira nacional. Ao Poder Legislativo cabe a apreciação desse projeto, a sua alteração com limites bem definidos, mediante a presentação de emendas e a sua posterior aprovação.

Após a aprovação e sanção dos instrumentos de planejamento (Plano Plurianual, Lei de Diretrizes Orçamentárias e Lei Orçamentária Anual), cabe ao Executivo conferir execução ao programa financeiro estipulado, contando, contudo, com mecanismos institucionais que permitam que a lei orçamentária seja vista apenas como instrumento autorizativo, sem caráter cogente, impositivo.

As emendas parlamentares ao orçamento se caracterizam, no presidencialismo de coalizão (ABRANCHES, 1988) como moedas de trocas recíprocas entre o Poder Executivo e o Congresso Nacional, negociadas com o objetivo de obter o apoio parlamentar aos projetos do governo, por um lado, bem como para a manutenção das bases eleitorais, mediante o atendimento de necessidades locais, de outro, desvirtuando, de forma nefasta, uma das principais ferramentas de efetiva participação do Poder Legislativo no processo orçamentário.

Contudo, o alegado caráter autorizativo do orçamento, até então, permitia uma grande supremacia por parte do Poder Executivo nesse jogo de interesses, já que muitas vezes condicionava a execução das emendas parlamentares ao apoio irrestrito dos parlamentares às suas iniciativas.

Diante das inovações constitucionais trazidas pela Emenda Constitucional n ${ }^{\circ} 86 / 2015$, atenuou-se a margem de discricionariedade do Poder Executivo no cumprimento do orçamento anual, ao conferir obrigatoriedade às emendas parlamentares individuais propostas na fase de sua análise, fazendo, assim, com que o seu caráter impositivo seja reforçado, em detrimento do entendimento atualmente dominante na doutrina e prática nacionais.

Este artigo objetiva analisar as possíveis implicações da Emenda Constitucional $\mathrm{n}$. 86/2015 nas relações estabelecidas entre os Poderes Executivo e Legislativo na elaboração e 
execução do orçamento brasileiro, partindo da hipótese de que tal medida, longe de conferir maior independência ao Poder Legislativo em sua tarefa de avaliar e contribuir para o planejamento e execução das políticas públicas, no atendimento das finalidades estatais precípuas, acaba por aprofundar as mazelas de nosso sistema político. Analisar-se-á, assim, como se davam tais relações antes da aprovação da EC n. 86/2015 e se houve realmente alterações que possam provocar uma alteração na dinâmica dessa relação político-institucional, pontuando-se os possíveis aspectos positivos e negativos dessa alteração. Para alcançar o objetivo proposto, utilizar-se-á de fontes predominantemente teóricas, em uma abordagem compreensivo-exploratória e crítico-reflexiva sobre a matéria.

\section{O ORÇAMENTO E OS INSTRUMENTOS DE PLANEJAMENTO NO BRASIL}

\subsection{Conceitos preliminares}

O sistema orçamentário brasileiro vigente compreende a elaboração de três leis que se interrelacionam para o estabelecimento do planejamento governamental, mediante a previsão das receitas e despesas públicas. O Plano Plurianual - PPA estabelece as diretrizes, objetivos e metas da Administração Pública para o próximo quadriênio, representando, assim, o planejamento governamental de longo prazo. A partir do conteúdo do PPA, elabora-se, anualmente, a Lei de Diretrizes Orçamentárias- LDO, que institui as metas e prioridades para o exercício financeiro subsequente. Dos dispositivos da LDO extraem-se as diretrizes para a elaboração da Lei Orçamentária Anual - LOA, que contém estimativa do total das receitas e fixação das despesas para o exercício fiscal subsequente, de forma a evidenciar a política econômica, financeira e o programa de trabalho da Administração Pública.

Em virtude dessa interrelação, o projeto da LOA deve ser elaborado de forma compatível com o PPA e com a LDO, sendo que nenhum investimento cuja execução ultrapasse um exercício financeiro poderá ser iniciado sem prévia inclusão no PPA, ou sem lei que autorize a inclusão, bem como nenhuma despesa pode ser realizada sem prévia inclusão orçamentária. A previsão constitucional dessa matéria é a seguinte:

Art. 165. Leis de iniciativa do Poder Executivo estabelecerão:

I - o plano plurianual;

II - as diretrizes orçamentárias;

III - os orçamentos anuais. 
$\S 1^{\circ}$ A lei que instituir o plano plurianual estabelecerá, de forma regionalizada, as diretrizes, objetivos e metas da administração pública federal para as despesas de capital e outras delas decorrentes e para as relativas aos programas de duração continuada.

$\S 2^{\circ}$ A lei de diretrizes orçamentárias compreenderá as metas e prioridades da administração pública federal, incluindo as despesas de capital para o exercício financeiro subseqüente, orientará a elaboração da lei orçamentária anual, disporá sobre as alterações na legislação tributária e estabelecerá a política de aplicação das agências financeiras oficiais de fomento.

$\S 3^{\circ} \ldots$

$\S 4^{\circ}$ Os planos e programas nacionais, regionais e setoriais previstos nesta Constituição serão elaborados em consonância com o plano plurianual e apreciados pelo Congresso Nacional.

$\S 5^{\circ}$ A lei orçamentária anual compreenderá:

I - o orçamento fiscal referente aos Poderes da União, seus fundos, órgãos e entidades da administração direta e indireta, inclusive fundações instituídas e mantidas pelo Poder Público;

II - o orçamento de investimento das empresas em que a União, direta ou indiretamente, detenha a maioria do capital social com direito a voto;

III - o orçamento da seguridade social, abrangendo todas as entidades e órgãos a ela vinculados, da administração direta ou indireta, bem como os fundos e fundações instituídos e mantidos pelo Poder Público.

$\S 6^{\circ} \ldots$

$\S 7^{\circ}$ Os orçamentos previstos no $\S 5^{\circ}$, I e II, deste artigo, compatibilizados com o plano plurianual, terão entre suas funções a de reduzir desigualdades inter-regionais, segundo critério populacional.

$\S 8^{\circ} \mathrm{A}$ lei orçamentária anual não conterá dispositivo estranho à previsão da receita e à fixação da despesa, não se incluindo na proibição a autorização para abertura de créditos suplementares e contratação de operações de crédito, ainda que por antecipação de receita, nos termos da lei.

$\S 9^{\circ}$

[...] (grifos nossos).

Dentre as vedações constitucionais estabelecidas em matéria orçamentária, destaca-se, conforme previsão do art. 167 da C.F./88:

- o início de programas ou projetos não incluídos na lei orçamentária anual;

- a realização de despesas ou a assunção de obrigações diretas que excedam os créditos orçamentários ou adicionais;

- a realização de operações de créditos que excedam o montante das despesas de capital, ressalvadas as autorizadas mediante créditos suplementares ou especiais com finalidade precisa, aprovados pelo Poder Legislativo por maioria absoluta;

- a abertura de crédito suplementar ou especial sem prévia autorização legislativa e sem indicação dos recursos correspondentes;

- a transposição, o remanejamento ou a transferência de recursos de uma categoria de programação para outra ou de um órgão para outro, sem prévia autorização legislativa;

- a concessão ou utilização de créditos ilimitados; a utilização, sem autorização 
legislativa específica, de recursos dos orçamentos fiscal e da seguridade social para suprir necessidade ou cobrir déficit de empresas, fundações e fundos, inclusive dos mencionados no art. $165, \S 5^{\circ}$;

- a instituição de fundos de qualquer natureza, sem prévia autorização legislativa.

Atualmente, o orçamento deixou de ser mera peça contábil, de conteúdo financeiro, para se constituir em instrumento "[...] de atuação do Estado perante a sociedade, nela intervindo e dirigindo seus rumos"(OLIVEIRA, 2007, p 304/305).

A partir desses conceitos preliminares, passaremos à análise sobre a natureza autorizativa ou impositiva da LOA, discussão essa que vem ocupando espaço destacado na doutrina pátria, conforme a seguir será demonstrado.

\subsection{A natureza da Lei Orçamentária Anual}

Muito se discute sobre a natureza da lei orçamentária. Aqueles que a entendem como impositiva alegam que não se pode exigir que as despesas previstas sejam contratadas, empenhadas, liquidadas e pagas. A previsão de despesas na LOA seria, assim, apenas um teto/limite negativo (HARADA, 2013), na qual as dotações servem apenas como pré-condição para que determinado gasto possa ser efetuado. Esse posicionamente é o predominante na doutrina brasileira e é o que vem sendo praticado em nosso país.

Arnaldo Sampaio de Moraes Godoy (2014), ao defender que o orçamento brasileiro é autorizativo, explica que:

O Poder Executivo deve, necessariamente, contar com alguma discricionariedade ao longo do processo de execução orçamentária. As vicissitudes da vida contemporânea exigem do Estado intervenções pontuais, abstenções, realocações, que indicam plasticidade institucional que o modelo democrático radicalmente exige. É nesse contexto que se espera um orçamento autorizativo, em detrimento do impasse gerado por um orçamento de conteúdo impositivo ou mandatório. [...] É a técnica do contingenciamento que permite medidas transitórias de contenção de gastos, de racionalização administrativa e de atuação estratégica por parte do Poder Executivo (GODOY, 2014, p.61-62).

O orçamento impositivo, por sua vez, traduz a ideia de que as previsões de despesa nele constantes seriam de execução obrigatória, negando-se ao Chefe do Poder Executivo a prerrogativa de contingenciar verbas com base em avaliações de conveniência e oportunidade (DALLARI, 2011). 
Os que defendem tal posicionamento alegam que a grande maioria das despesas vinculadas na peça orçamentária são de natureza obrigatória, tais como gastos com saúde, educação, despesas com pessoal e amortização da dívida, que não podem ser objeto de contingenciamento, nos termos do art. $9^{\circ}, \S 2^{\circ}$ da Lei Complementar n. 101/2000 ${ }^{3}$, restando, assim, pouca margem de manobra para o Executivo elaborar e executar a LOA.

O Supremo Tribunal Federal (STF), na ADI 46663/RO, deixou evidenciado uma possível alteração do entendimento predominante de que a LOA é apenas autorizativa. É a conclusão que se extrai do voto do Ministro Luiz Fux, proferido em $2012^{4}$ :

\begin{abstract}
[...] As normas orçamentárias ostentam, segundo a lição da moderna doutrina financista, a denominada força vinculante mínima, a ensejar a imposição de um dever prima facie de acatamento, ressalvada a motivação administrativa que justifique o descumprimento com amparo no postulado da razoabilidade, sejam elas emanadas da proposta do Poder Executivo ou fruto de emenda apresentada pelo Poder Legislativo, de modo que a atribuição de regime formal privilegiado exclusivamente às normas oriundas de emendas parlamentares viola a harmonia entre os poderes políticos $(\mathrm{CF}$, art. $\left.2^{\circ}\right)^{5}$.
\end{abstract}

A promulgação da Emenda Constitucional n. 86/2015, ao prever a execução obrigatória das emendas parlamentares individuais, enseja a interpretação de que o restante da LOA não tem a mesma qualidade, já que a execução orçamentária seria obrigatória apenas para as emendas parlamentares individuais (HARADA, 2013).

Diante dos apontamentos acima expressos, entendemos que a lei orçamentária possui uma natureza mista: a efetivação das despesas não é obrigatória simplesmente pelo fato de estarem projetadas no orçamento. Contudo, a maior parte das despesas orçamentárias no Brasil e, também, as emendas parlamentares individuais, são impostas por força constitucional ou legal, o que as torna essencialmente obrigatórias.

\title{
2 O PAPEL DO PODER LEGISLATIVO NA APRECIAÇÃO E DEFINIÇÃO DA PROPOSTA ORÇAMENTÁRIA ANUAL
}

\footnotetext{
${ }^{3}$ Art. 90 [...]§ $2^{\circ}$ Não serão objeto de limitação as despesas que constituam obrigações constitucionais e legais do ente, inclusive aquelas destinadas ao pagamento do serviço da dívida, e as ressalvadas pela lei de diretrizes orçamentárias.

${ }^{4}$ Posteriormente, tal entendimento foi corroborado pelo Ministro Marco Aurélio. A discussão foi interrompida por pedido de vista e acabou perdendo seu objeto, pelo exaurimento da eficácia da lei impugnada.

${ }^{5}$ Disponível em: <http:/ www.stf.jus.br/portal/processo/verProcessoTexto.asp?id=3094993\&tipoApp=RTF>.

Acesso em: 3 set. 2016.
} 
Pelos dispositivos constitucionais anteriormente mencionados, percebe-se o protagonismo do Poder Executivo na elaboração da proposta orçamentária, vez que competelhe a iniciativa das leis pertinentes e a gestão financeira do Estado. Contudo, cabe ao Poder Legislativo relevante papel na definição das políticas públicas e na forma de sua implementação, pois a ele compete a aprovação das leis orçamentárias (PPA, LDO e LOA), bem como a autorização prévia de suas eventuais alterações, conforme se dessume do art. 167 da C.R./88.

O art. 166 da C.R/88 estabelece de forma mais detalhada como se dará a participação do Poder Legislativo na apreciação desses projetos de lei e em que medida o Poder Legislativo pode alterar a proposta orçamentária enviada à sua apreciação pelo Poder Executivo. Vejamos:

Art. 166. Os projetos de lei relativos ao plano plurianual, às diretrizes orçamentárias, ao orçamento anual e aos créditos adicionais serão apreciados pelas duas Casas do Congresso Nacional, na forma do regimento comum.

$\S 1^{\circ}$ Caberá a uma Comissão mista permanente de Senadores e Deputados:

I - examinar e emitir parecer sobre os projetos referidos neste artigo e sobre as contas apresentadas anualmente pelo Presidente da República;

$[\ldots]$

$\S 2^{\circ}$ As emendas serão apresentadas na Comissão mista, que sobre elas emitirá parecer, e apreciadas, na forma regimental, pelo Plenário das duas Casas do Congresso Nacional.

$\S 3^{\circ}$ As emendas ao projeto de lei do orçamento anual ou aos projetos que o modifiquem somente podem ser aprovadas caso:

I - sejam compatíveis com o plano plurianual e com a lei de diretrizes orçamentárias; II - indiquem os recursos necessários, admitidos apenas os provenientes de anulação de despesa, excluídas as que incidam sobre:

a) dotações para pessoal e seus encargos;

b) serviço da dívida;

c) transferências tributárias constitucionais para Estados, Municípios e Distrito Federal; ou

III - sejam relacionadas:

a) com a correção de erros ou omissões; ou

b) com os dispositivos do texto do projeto de lei.

$\S 4^{\circ}$ As emendas ao projeto de lei de diretrizes orçamentárias não poderão ser aprovadas quando incompatíveis com o plano plurianual.

$[\ldots]$

Sobre o papel do Poder Legislativo na seara orçamentária, assim se expressa Eduardo Mendonça (2015):

Nesse cabo de guerra, o Poder Executivo assume um protagonismo natural. Não apenas por conta da sua iniciativa privativa para remeter os projetos de lei, mas sobretudo pelo domínio da informação pulverizada acerca da imensa maioria dos órgãos responsáveis pelos gastos. Na prática, é impossível que o Legislativo faça uma revisão minuciosa de cada uma das dotações individuais, contadas na casa dos 
milhões. Em vez disso, o verdadeiro papel institucional do Congresso seria o de analisar e influenciar as macroescolhas orçamentárias, pelas quais são ordenadas as prioridades da atuação estatal. [...] O legislador não consegue refazer todo esse mosaico, mas poderia discutir suas grandes linhas. Em paralelo, poderia igualmente examinar em maior detalhe setores selecionados, estabelecendo um diálogo de qualidade em relação às principais escolhas políticas do Governo.

E complementa o mesmo autor:

A deliberação do orçamento é o momento em que os diferentes segmentos da sociedade, representados pelos parlamentares, deveriam discutir a destinação do dinheiro disponível, o que implica decidir quais interesses serão favorecidos e em quais medidas. Ao fim e ao cabo, é aqui que as políticas públicas começam a ganhar contornos concretos, pelo menos na delimitação do formato e tamanho que poderão assumi. (MENDONÇA, 2015).

Godoy (2014) assim sintetiza o procedimento prévio à aprovação da LOA:

\begin{abstract}
A proposta originária da lei orçamentária é encaminhada pelo Ministério do Planejamento, Orçamento e Gestão à Presidência da República. O titular do Executivo Federal, em seguida, encaminha o texto ao Congresso Nacional. No Legislativo, uma comissão examina a proposta, passo que é acompanhado de audiências públicas, bem como de propostas de emendas parlamentares. O texto original, depois de receber as propostas de emendas parlamentares, segue para a comissão que o apreciou, de onde segue para discussão em Plenário. Depois de aprovado, segue para sanção presidencial. O Chefe do Executivo poderá aprová-lo, poderá vetá-lo parcialmente, bem como poderá vetá-lo integralmente. As razões do veto seguem ao Presidente do Senado. Sessão conjunta do Senado e da Câmara pode qualificar a rejeição do veto (GODOY, 2014, p. 61).
\end{abstract}

Interessa a este estudo as emendas parlamentares. Veremos, pois, como funciona esse dispositivo e quais os seus principais reflexos na relação entre o Poder Executivo e o Poder Legislativo, considerando as peculiaridades do sistema presidencialista nacional.

\title{
3 EMENDAS PARLAMENTARES À LEI ORÇAMENTÁRIA ANUAL
}

As emendas parlamentares se caracterizam como um dos mais relevantes instrumentos que o Congresso Nacional possui para participar da elaboração do orçamento anual. Em tese, por meio das emendas, os parlamentares procuram aperfeiçoar a proposta encaminhada pelo Poder Executivo, visando uma melhor alocação dos recursos públicos. Explicitaremos aqui os principais contornos legais e regimentais que regem a propositura de tais emendas.

Segundo o já citado art. 166 da C.R./88, as emendas ao projeto da LOA ou aos projetos que o modifiquem somente podem ser aprovadas caso: sejam compatíveis com o PPA e com a 
LDO; sejam relacionadas com a correção de erros ou omissões ou com os dispositivos do texto do projeto de lei e indiquem os recursos necessários, admitidos apenas os provenientes de anulação de despesa, excluídas as que incidam sobre: a) dotações para pessoal e seus encargos; b) serviço da dívida; c) transferências tributárias constitucionais para Estados, Municípios e DF.

$\mathrm{O}$ art. 33 da Lei Federal n. 4.320/64 estatui que não se admitirão emendas ao projeto da LOA que visem: alterar a dotação solicitada para despesa de custeio, salvo quando provada, nesse ponto a inexatidão da proposta; conceder dotação para o início de obra cujo projeto não esteja aprovado pelos órgãos competentes; conceder dotação para instalação ou funcionamento de serviço que não esteja anteriormente criado; e conceder dotação superior aos quantitativos previamente fixados para concessão de auxílios e subvenções.

As emendas são apresentadas na Comissão Mista do orçamento - CMO, que sobre elas emitirá parecer, e são apreciadas, na forma regimental, pelo Plenário das duas Casas do Congresso Nacional. Podem propor emendas: os deputados e senadores (emendas individuais), as comissões permanentes (emendas coletivas) e as bancadas estaduais (emendas coletivas).

As regras regimentais que disciplinam as emendas parlamentares estão na Resolução Conjunta $\mathrm{n}^{\circ}$ 01/2006 do Congresso Nacional. Destaquemos, a partir de agora, as suas principais disposições.

As emendas de Comissões Permanentes (arts. 44 e 45) seguem as seguintes regras: Podem ser propostas até oito emendas por Comissão das duas Casas. As emendas devem ter caráter institucional e representar o interesse nacional, vedada a destinação a entidades privadas, salvo se contemplarem programação constante do projeto da LOA. As emendas devem conter em sua justificação, elementos, critérios e fórmulas que determinem a aplicação dos recursos em função da população beneficiada. As comissões permanentes só podem sugerir o remanejamento de recursos no âmbito de suas respectivas áreas temáticas, tendo ainda de conservar a natureza inicial da despesa (investimento, despesa corrente, etc.). Não podem, portanto, propor o remanejamento entre áreas.

As emendas de Bancadas Estaduais (arts. 46 a 48) devem tratar de matérias de interesse de cada Estado ou Distrito Federal. Podem ser propostas no mínimo, quinze e no máximo vinte e três emendas, podendo variar, a depender do número de parlamentares de cada bancada. É obrigatório identificar de forma precisa seu objeto, vedada a designação genérica de programação que possa contemplar obras distintas ou possam resultar, na execução, em 
transferência voluntária para mais de um ente federativo ou entidade privada. No caso de projetos, devem contemplar projeto de grande vulto ou estruturante, especificando $\square$ se o seu objeto e localização. Em sua justificação, as emendas conterão, no mínimo: os elementos necessários para a avaliação do custo $\square$ benefício da ação pretendida e seus aspectos econômico $\square$ sociais; valor total estimado, em caso de projeto; demais fontes de financiamento e eventuais contrapartidas. As bancadas estaduais só podem remanejar recursos no âmbito das dotações originalmente atribuídas aos respectivos entes federativos, exigindo-se ainda que as verbas remanejadas permaneçam destinadas ao mesmo órgão e que a despesa conserve sua natureza inicial.

Quanto às emendas individuais (arts. 49 e 50), a Resolução Conjunta n. 001/20016 já foi devidamente atualizada de acordo com a EC n. 86/2015. Podem ser propostas até vinte e cinco emendas por parlamentar. Elas devem atender às disposições da LDO e, no caso de projetos, resultar, em seu conjunto, em dotação suficiente para conclusão de obra ou da etapa do cronograma de execução a que se refere. As emendas individuais são de natureza impositiva e correspondem a $1,2 \%$ da receita corrente líquida prevista no projeto da LOA enviado pelo Executivo, distribuído pela quantidade de parlamentares no exercício do mandato.

\section{A COMPOSIÇÃO DE FORÇAS DOS PODERES NA ELABORAÇÃO E EXECUÇÃO DA LOA ANTES DA EC N. 86/2015: TRAÇOS DO RELACIONAMENTO ENTRE O PODER EXECUTIVO E O PODER} LEGISLATIVO 6

Considerando a natureza autorizativa da LOA, de acordo com a prática corrente em nosso país, a propositura de emenda e a sua aprovação, antes da promulgação da EC n. 86/2015, não garantiam que o projeto da LOA, uma vez aprovado e sancionado, fosse implementado. Embora os parlamentares tenham o direito de propor emendas (individuais e coletivas), cabia ao Executivo determinar quais delas seriam executadas, na dependência de recursos do Tesouro Nacional.

\footnotetext{
${ }^{6} \mathrm{O}$ fato de cá usarmos todos os verbos em tempos passados não significa que as constatações aqui lançadas serão diferentes a partir da aplicação da EC n. 86/2015. Teremos que aguardar a maturação de sua execução para efetivamente verificar os seus efeitos na dinâmica do relacionamento entre os Poderes Executivo e Legislativa na elaboração e execução orçamentárias.
} 
Dessa forma, um dos mecanismos de flexibilidade orçamentária ${ }^{7}$ qual seja, o contingenciamento $^{8}$, acabava sendo utilizado para além das hipóteses previstas em lei, colocando, assim, a priori, o Executivo em posição mais favorável do que o Legislativo. (PEREIRA; MUELLER, 2002).

As emendas parlamentares, que "[...] visam influenciar as decisões de política pública e, como tal, são iniciativas legítimas no processo legislativo”, contudo, passaram a ser vistas, no Brasil, "como mecanismos ilegítimos e escusos de barganha política em virtude de sua estreita vinculação com jogos de patronagem e corrupção.” (MELO, 2006, p. 197).

O Executivo fazia pressão sobre a atuação dos parlamentares, já que tinha o poder discricionário de executar ou não as emendas. Sua atuação estratégica era ainda facilitada pela falta de sincronia entre a receita efetivamente realizada e as despesas. Exemplos de tal forma atuação foram a aprovação do salário mínimo em 2000 e o aborto da Comissão Parlamentar de Inquérito de 2001, que investigaria denúncias de corrupção no governo Fernando Henrique Cardoso (PEREIRA: MUELLER, 2002).

O Executivo recompensava os parlamentares que sistematicamente votavam a favor dos projetos de interesse do governo, autorizando a execução de suas emendas, e punia os que não votavam nesses projetos, não executando as emendas propostas por eles. Após a aprovação e sanção da LOA, o Executivo procedia à modificação do orçamento, mediante créditos adicionais que possibilitavam introduzir novas emendas com potencial de distribuir recursos ${ }^{9}$.

Destarte, pode-se afirmar que uma das causas do uso das emendas como objeto de troca estaria no caráter autorizativo conferido ao orçamento (VOLPE; CAMBRAIA, 2015), o que acabava por comprometer justamente aquele que seria o principal papel do Poder

\footnotetext{
${ }^{7}$ A esse propósito Dallaverde comenta que: "Consistem os mecanismos de flexibilidade em instrumentos voltados à realização de alterações no orçamento público aprovado, diante da ocorrência de situações não previstas à época da elaboração e aprovação da proposta orçamentária, que passam a ser vivenciadas no decorrer da execução do orçamento." (DALLAVERDE, 2013, p. 119).

${ }^{8}$ Sobre o contingenciamento, oberve-se que é um "[..] mecanismo de flexibilidade orçamentária que permite ao Poder Executivo deixar de realizar certas despesas em virtude da ausência de recursos voltados à sua consecução, decorrente essencialmente da arrecadação de receitas em montante inferior àquele previsto na lei orçamentária anual. " (DALLAVERDE, 2013, p. 135). Vide art. $9^{\circ}$, $2^{\circ}$ da Lei Complementar n. 101/2000 - Lei de Responsabilidade Fiscal.

${ }^{9}$ Essa forma de atuação persiste, mesmo após a EC n. 86/2015, em virtude de dois dos instrumentos de alteração orçamentária: a) os créditos adicionais suplementares, abertos nos limites estabelecidos pela LOA, que implicam na redistribuição de recursos sem gerar novas despesas e podem ser realizados via decreto presidencial; b) os créditos adicionais especiais, que são créditos que ultrapassam os limites autorizados na LOA ou que correspondem a atividade ou projetos novos, sem associação anterior a qualquer alocação orçamentária. Esses últimos dependem de aprovação do Congresso Nacional (maioria simples), que, todavia, não tem poderes para alterar a destinação dos recursos nem para mudar o valor do crédito proposto.
} 
Legislativo: influir nas decisões políticas fundamentais, que acabam sendo monopolizadas pelo Executivo (MENDONÇA, 2015).

Marcelo Vaz Ferreira (2007) afirma que:

\begin{abstract}
Em relação às despesas discricionárias, fica aberta a possibilidade de que o poder executivo, quando discorde de algumas despesas aprovadas, tome medidas que inviabilizem a sua execução, ou que utilize a sua liberação como uma forma de influenciar no comportamento dos parlamentares, ou de barganhar a aprovação de leis de seu interesse, influenciando no jogo politico (FERREIRA, 2007, p.56).
\end{abstract}

A primeira conclusão a que chegamos é que o Executivo até então, dispunha de um conjunto de instrumentos institucionais que garantiam sua preponderância nas relações com o Legislativo (PEREIRA; MUELLER, 2002). As emendas parlamentares individuais eram, pois, instrumentos para negociar as preferências do Executivo com a sua coalização no Congresso, caracterizando-se, assim, como incentivo, em troca de apoio aos projetos de interesse do Executivo ("moeda de troca").

Tal forma de atuação pode ser atribuída principalmente ao denominado presidencialismo de coalizão, típico dos países sul americanos, que nas palavras do autor que cunhou tal expressão, Sérgio Abranches (1988), seria:

[...] um sistema caracterizado pela instalibilidade, de alto risco e cuja sustentação baseia-se quase exclusivamente no desempenho corrente do governo e de respeitar estritamente os pontos ideológicos ou programáticos considerados inegociáveis, os quais nem sempre são explícita e coerentemente fixados na fase de formação da coalizão (ABRANCHES, 1988, p.27).

A segunda conclusão a que chegamos é que, não obstante a preponderância do Executivo nesse locus, isso não significa que os parlamenteras não colham frutos dessa forma de atuação. Trata-se, em verdade, de uma via de mão dupla. Hélio Tollini (2008) afirma que,

[...] a existência das emendas individuais tem interessado tanto ao Poder Legislativo quanto ao Poder Executivo. Enquanto os parlamentares beneficiam-se politicamente com a possibilidade de destinar recursos federais para as suas bases eleitorais, o Poder Executivo utiliza as emendas como mecanismo de cooptação em suas relações com os partidos, ao aproveitar do caráter autorizativo da LOA para condicionar a execução das emendas individuais à votação pelos parlamentares dos projetos de interesse do Executivo nas votações do Congresso Nacional (TOLLINI, 2008, p. 15).

As emendas parlamentares individuais visam, assim, direcionar para as respectivas bases eleitorais programas e projetos de interesse local, com o objetivo de beneficiar as 
principais bases eleitorais, a fim de maximizar o futuro eleitoral e a carreira do parlamentar (PEREIRA; MUELLER, 2002).

Essa "troca de favores" é possibilitada por vários fatores, que podemos assim sintetizar: As regras eleitorais produzem incentivos para o comportamento individualista dos parlamentares e as cláusulas de barreiras favorecem a fragmentação partidária; o federalismo fortalece as lealdades políticas de caráter local e regional, que faz com que o Executivo fique refém de um Congresso voltado para questões locais; a representação proporcional com grandes distritos em um sistema político multiparidário dificulta a composição com o Congresso e aumenta a probabilidade de surgirem governos fracos (PEREIRA; MULLER 2002).

O benefício para o parlamentar decorrente desse sistema é, principalmente, o uso eleitoral das emendas, na medida em que determinada obra ou ação fica vinculada ao seu nome. Ainda que seja baixo o valor em dinheiro, é grande o apelo popular dessas ações. Nas palavras de Mendonça:

\begin{abstract}
A ideia de direcionar recursos para os próprios redutos eleitorais é relativamente intuitiva. Não apenas pelas vantagens competitivas que isso pode gerar em futuras campanhas eleitorais, mas até mesmo pela natural proximidade do parlamentar com a realidade do seu local de origem (MENDONÇA, 2015).
\end{abstract}

Assim, quanto maior o valor das emendas executadas de um parlamentar, maior as suas chances de reeleição, o que explica o contentamento dos parlamentares com um papel tão reduzido no processo de elaboração do orçamento ${ }^{10}$.

Por sua vez, a frequência com que o deputado votava a favor do governo aumentava a probabilidade de suas emendas serem executadas. De outro lado, quanto maior a proporção de emendas executadas de um deputado, mais vezes ele votaria com o governo (PEREIRA; MUELLER, 2002). Em suma: As emendas asseguram a sobrevivência política dos parlamentares e o seu êxito eleitoral.

Com respeito à relação Executivo_Legislativo, Fernando Limongi e Argelina discordam das principais teses sobre o uso do orçamento e emendas individuais como "moeda de troca”. Segundo os autores:

O problema da tese das emendas como "moedas de troca" está em seus supostos.

\footnotetext{
${ }^{10}$ Segundo Eduardo Mendonça, "Há muito significado no fato de o Congresso mostrar-se tão ofendido com a retenção das emendas orçamentárias individuais, ao mesmo tempo em que encara com naturalidade o contingenciamento de todo o resto" (2015)
} 
Supõe-se que os legisladores têm um interesse comum, qual seja, o da promoção de políticas distributivistas, uma vez que estas garantiriam (ou afetariam positivamente) suas chances de obter a reelei- ção. Por extensão, os interesses comuns dos parlamentares são tomados como contrários aos interesses do Executivo. Os dois Poderes estariam imersos em uma relação conflituosa, um jogo de soma zero. Assim, ao executar recursos alocados por emendas individuais, o presidente o faria às expensas de suas próprias prioridades.

Esses argumentos perdem de vista o básico: a principal linha de conflito do sistema político brasileiro não é dada pelas relações entre os poderes, mas sim pelas clivagens político-partidárias. Parlamentares dividem-se em dois grandes campos, os que apóiam e os que se opõem ao Executivo. Essa distinção implica que a maioria apóia a centralização da condução do processo orçamentário em sua fase congressual. Há uma delegação de poder das bases para as lideranças partidárias, nesse caso representadas pelo relator geral e seus colaboradores diretos. Essa delegação explica o papel reduzido que as emendas individuais desempenham na participação do Congresso no processo orçamentá- rio e a importância que as variáveis macroeconômicas assumem para os relatores. Antes de tudo, o orçamento visa a garantir o sucesso da política do governo, especialmente a econômica (LIMONGI; FIGUEIREDO, 2005, p. $766^{11}$ ).

Ademais, ponderam que:

Quanto às prioridades de um e outro poder, expressas na alocação de recursos orçamentários, as diferenças são muito pequenas. Não há agendas conflitantes. Mais especificamente, ao executar recursos alocados por parlamentares mediante emendas individuais, o Executivo não está cedendo a pressões e deixando de executar a sua agenda. A 766 Fernando Limongi e Argelina Figueiredo Revista Dados - 2005 - Vol. 48 no $41^{\text {a }}$ Revisão: 12.01.2006 - 2 ${ }^{\mathrm{a}}$ Revisão: 15.02.2006 Cliente: Iuperj - Produção: Textos \& Formas alocação de recursos feita pelos legisladores é complementar, e não contrária, à do Executivo. Este é capaz de canalizar as demandas dos parlamentares e acomodá-las no interior dos programas por ele definidos como prioritários. Ao executar emendas de parlamentares da oposição e/ou da situação que não o apóiam, o Executivo está simplesmente executando a sua agenda. $\mathrm{O}$ controle do processo pelo Executivo é de tal ordem que nem mesmo os parlamentares da oposição têm como propor emendas que constituam uma agenda alternativa à proposta pelo governo (LIMONGI; FIGUEIREDO, p. 766/767 12 ).

\section{CONSEQUÊNCIAS DA FORMA DE RELACIONAMENTO ENTRE O EXECUTIVO E O LEGISLATIVO NA ELABORAÇÃO E EXECUÇÃO DA LOA ANTES DA EC N. 86/2015}

A negociação de emendas parlamentares individuais entre os poderes, como forma de assegurar o apoio político para a governabilidade ${ }^{13} \mathrm{e}$, ao mesmo tempo, garantir um melhor

\footnotetext{
${ }^{11}$ Disponível em: <http://www.scielo.br/pdf/dados/v48n4/28478.pdf>. Acesso em: 3 set. 2016.

${ }^{12}$ Disponível em: <http://www.scielo.br/pdf/dados/v48n4/28478.pdf>. Acesso em: 3 set. 2016.

13 "São as trocas de apoio por políticas distributivistas, na forma de emendas orçamentárias, que fazem com que o sistema político brasileiro funcione, mas esse funcionamento é subótimo, ineficiente.”(RENNÓ, 2006)
} 
desempenho eleitoral por parte dos parlamentares, acabava por "criar estímulos e práticas corruptas, ilegais, que se confundem com com clientelismo, nepotismo e outras variações de patrimonialismo $^{14}$ [...]" (RENNÓ, 2006, p. 266), já que as emendas não eram (e ainda não são) elaboradas para aprimorar o cumprimento dos instrumentos de planejamento.

Embora o presidencialismo de coalizão propicie condições para que o Executivo obtenha, a um baixo custo, alto grau de governabilidade, (PEREIRA; MUELLER, 2002), já que é barato manter disciplinada a coalização do Executivo no Congresso por intermédio das emendas parlamentares individuais, institucionalmente o prejuízo é enorme, pois "[...] raramente o presidente consegue evitar pagar um alto preço, na forma de clientelismo e fisiologismo, em troca de apoio parlamentar." (AMES, 2003, p. 239).

Por sua vez, a aprovação de programas distributivos entre parlamentares proporcionava maiores gastos à medida que aumentava o número de parlamentares de diferentes partidos políticos, corroborando a conclusão de Pereira e Muller de que "[...] coalizões instáveis provocam orçamentos maiores" (2002, p. 266).

Podemos, então, concluir que o uso político dos recursos públicos nas formas de patronagem, clientelismo e patrimonialismo gera um alto custo para o Brasil e impede que o governo priorize as preferências da maioria através de soluções coletivas (PEREIRA; MUELLER, 2002).

\section{A EMENDA CONSTITUCIONAL N. 86/2015: REFLEXÕES SOBRE SEUS EFEITOS NO RELACIONAMENTO ENTRE O EXECUTIVO E O LEGISLATIVO NA ELABORAÇÃO E EXECUÇÃO DA LOA}

A EC 86/2015, promulgada em março de 2015, estabeleceu a impositividade das emendas parlamentares individuais, nos seguintes termos:

\footnotetext{
As Mesas da Câmara dos Deputados e do Senado Federal, nos termos do $\S 3^{\circ}$ do art. 60 da Constituição Federal, promulgam a seguinte Emenda ao texto constitucional: Art. $1^{\circ}$ Os arts. 165, 166 e 198 da Constituição Federal passam a vigorar com as seguintes alterações:

"Art. 165.

$\S 9^{\circ}$
}

\footnotetext{
${ }^{14} \mathrm{O}$ termo patrimonialismo identifica a confusão entre as esferas pública e privada, fazendo com que os agentes a serviço do Estado encarem sua atividade como parte do seu interesse particular, concedendo favores, apadrinhando e se locupletando à custa de sua posição" (MENDONÇA, 2015).
} 
III - dispor sobre critérios para a execução equitativa, além de procedimentos que serão adotados quando houver impedimentos legais e técnicos, cumprimento de restos a pagar e limitação das programações de caráter obrigatório, para a realização do disposto no $\S 11$ do art. 166."(NR)

"Art. 166.

$\S 9^{\circ}$ As emendas individuais ao projeto de lei orçamentária serão aprovadas no limite de $1,2 \%$ (um inteiro e dois décimos por cento) da receita corrente líquida prevista no projeto encaminhado pelo Poder Executivo, sendo que a metade deste percentual será destinada a ações e serviços públicos de saúde. (Incluído pela Emenda Constitucional $\mathrm{n}^{\mathrm{o}} 86$, de 2015)

$\S 10 \ldots$

$\S 11$. É obrigatória a execução orçamentária e financeira das programações a que se refere o $\S 9^{\circ}$ deste artigo, em montante correspondente a 1,2\% (um inteiro e dois décimos por cento) da receita corrente líquida realizada no exercício anterior, conforme os critérios para a execução equitativa da programação definidos na lei complementar prevista no $\S 9^{\circ}$ do art. 165. (Incluído pela Emenda Constitucional $\mathrm{n}^{\circ}$ 86 , de 2015)

$\S 12$. As programações orçamentárias previstas no $\S 9^{\circ}$ deste artigo não serão de execução obrigatória nos casos dos impedimentos de ordem técnica. ${ }^{15}$ (Incluído pela Emenda Constitucional no 86 , de 2015)

$\S 13[\ldots]$

$\S 14$. No caso de impedimento de ordem técnica, no empenho de despesa que integre a programação, na forma do $\S 11$ deste artigo, serão adotadas as seguintes medidas: (Incluído pela Emenda Constitucional nº 86, de 2015)

[...]

$\S 15$. Após o prazo previsto no inciso IV do $\S 14$, as programações orçamentárias previstas no $\S 11$ não serão de execução obrigatória nos casos dos impedimentos justificados na notificação prevista no inciso I do $\S 14$. (Incluído pela Emenda Constitucional $\mathrm{n}^{\circ} 86$, de 2015)

$\S 16[\ldots]$

$\S 17$. Se for verificado que a reestimativa da receita e da despesa poderá resultar no não cumprimento da meta de resultado fiscal estabelecida na lei de diretrizes orçamentárias, o montante previsto no $§ 11$ deste artigo poderá ser reduzido em até a mesma proporção da limitação incidente sobre o conjunto das despesas discricionárias. (Incluído pela Emenda Constitucional nº 86, de 2015)

$\S 18$. Considera-se equitativa a execução das programações de caráter obrigatório que atenda de forma igualitária e impessoal às emendas apresentadas, independentemente da autoria (Incluído pela Emenda Constitucional nº 86, de 2015). [...]

A partir desse novo tratamento constitucional às emendas parlamentares individuais, espera-se que essa regra impositiva coloque fim[...] à subserviência do Legislativo em relação ao Executivo", além de "limitar o pouco republicano balcão de negócios que tem sido estabelecido, entre esses dois Poderes, em torno da execução orçamentária” (MENDONÇA,

\footnotetext{
${ }^{15}$ Impedimento de ordem técnica pode ser entendido como elementos que obstem o curso regular da realização da despesa referente à emenda individual de execução obrigatória. São exemplos de impedimentos de ordem técnica: 1) Não indicação do beneficiário e respectivo valor da emenda no prazo estabelecido. 2) Não apresentação do plano de trabalho no prazo. (BRASIL. MPOG, 2015. Orçamento Impositivo Orientações: Procedimentos, Prazos e Responsabilidades. Disponível em: $<$ http://www.orcamentofederal.gov.br/biblioteca/publicacoes_tecnicas/CARTILHA\%20IMPOSITIVO_05_02.p df>. Acesso em: 10 jul. 2016.
} 
2015). Também argumenta-se que tal dispositivo fortalecerá a hegemonia parlamentar nas questões orçamentárias, além de contribuir para que o orçamento seja cumprido de maneira mais fiel.

Contudo, em uma análise mais abrangente, percebe-se que a emenda constitucional apenas impõe uma "[...] blindagem na execução das emendas individuais, inexistente em relação às demais dotações” (MENDONÇA, 2015), apresentando um alcance por demais restrito.

Em verdade, a constitucionalização da impositividade das emendas individuais é uma desvalorização da atuação do Poder Legislativo na definição do conteúdo orçamentário, já que a discussão prioriza detalhes de natureza fisiológica, conforme anteriormente demonstrado ${ }^{16}$. As emendas são propostas, em geral, de forma descontextualizada do planejamento do Poder Executivo e, por issso, mostram-se inócuas na implementação de qualquer política pública. Em verdade, na sua propositura, a intenção não é aprimorar qualquer ação de interesse público. Nos dizeres de Mendonça (2015), “as emendas individuais são uma autêntica cota pessoal de orçamento", eis que os parlamentares buscam apenas destinar essa fração dos recursos orçamentários para aplicá-los em benefício direto de seus eleitores imediatos, nada mais. Importante ainda reproduzir importante fala desse autor:

\begin{abstract}
A emenda [...] reforça a lógica de cota pessoal, tornando-a imune à própria dinâmica do debate político. Em outras palavras, não interessa se determinada opção de investimento é melhor do que outras ou simplesmente boa. O importante é que cada agente possa dispor do seu quinhão de verbas públicas. Trata-se de uma espécie de naturalização do nosso atávico patrimonialismo, que certamente não contribui em nada para a sua contenção. Em um ambiente de recursos ilimitados, o resultado dessa combinação já seria questionável pela indução do clientelismo e pelo consequente desequilíbrio que pode ocasionar no processo eleitoral. $E$ isso não apenas na disputa pelas reeleições dos próprios deputados e senadores, mas também nos planos estadual e, sobretudo, municipal - potencialmente influenciáveis pela alocação de verbas federais [...] No mínimo, abre-se mão daquela que seria a principal função do orçamento: permitir o cotejo amplo, racional e público entre todas as receitas disponíveis e todas as opções de despesa [...]A EC 86, ao modificar um aspecto pontual da atual praxe orçamentária brasileira, parece referendar todo o restante - esse sim marcado pelo menosprezo à possível contribuição institucional do Poder Legislativo (MENDONÇA, 2015).
\end{abstract}

Conta-nos o supracitado autor que nos Estados Unidos esse tipo de emenda possui um sentido pejorativo e são denominadas de pork barrel:

\footnotetext{
${ }^{16}$ Segundo Mendonça (2015), a EC n. 85/2015 apenas confirma a pouca disposição do Congresso para interferir verdadeiramente na formatação das grandes políticas públicas, substituída por uma lógica paroquial e personalista.
} 
[...] provavelmente em alusão a um costume, anterior à guerra civil, em que escravos recebiam um barril com porco salgado e eram incitados a lutar pela prenda. O sentido é claro: disputa pela apropriação individual de algo inicialmente coletivo. Na moderna política americana, o pork barrel ocorre tipicamente por meio de negociações individuais entre os congressistas (MENDONÇA, 2015).

Ademais, como a margem de discrionariedade do Poder Executivo na elaboração do orçamento já é pequena, as emendas obrigatórias estrangulam mais essa discricionariedade, aumentando a resistência de se cumprir a LOA quanto às demais previsões ( HARADA, 2013).

Registre-se ainda, também de acordo com Harada (2013), o estímulo à superavaliação da receita orçamentária, de forma que o orçamento real acaba sendo o decreto de contingenciamento - incentivo ao caráter fictício do orçamento.

Como o restante do orçamento (excetuadas as despesas não passíveis de contingenciamento) permanece tão autorizativo como antes, mantém-se a possiblidade de o Poder Executivo atuar de forma discricionária, na liberação ou não das demais dotações previstas. De nada adianta, pois, assegurar a impositividade às emendas individuais se as escolhas de investimento aprovadas pelo Congresso Nacional podem não se concretizar. Caímos, mais uma vez, no desprestígio do Poder Legislativo, com a sua própria anuência.

Além de estabelecerem despesas obrigatórias em dissonância com o PPA e LDO, podemos listar ainda como pontos negativos da EC n. 86/2015 o fato de ferirem a igualdade no processo eleitoral, em relação à participação dos futuros candidatos a deputado e senador, que não possuem o mesmo poder de convencimento e barganha em relação ao eleitor, além de tirar o poder de veto do Chefe do Poder Executivo, que se torna "refém" do Congresso Nacional, aprofundando, ainda mais, os discutíveis mecanismos de obtenção de governalidade peculiares ao presidencialismo de coalizão.

Por fim, menciona-se que tal emenda, além de limitar a discricionariedade do Poder Executivo, representa desobediência à harmonia e independência entre os Poderes, por determinar recorrente intervenção do Poder Legislativo em campo de atuação do Poder Executivo, ferindo-se o regime da intangibilidade do bloco constitucional sensível (GODOY, 2014).

\section{CONCLUSÃO}

Este artigo analisou, a partir da previsão constitucional e legal das normas que 
disciplinam o orçamento brasileiro, a sua natureza, bem como o papel dos poderes Executivo e Legislativo em sua elaboração e execução, a partir da promulgação da Emenda Constitucional n. 86/2015, que estabeleceu a impositividade das emendas parlamentares individuais propostas ao projeto da lei orçamentária enviado ao Congresso Nacional pelo Poder Executivo.

Constatou-se que a LOA não é puramente autorizativa e nem impositiva, tratando-se, portanto, de lei de caráter misto, com alguns dispositivos necessariamente impositivos e outros de natureza autorizativa.

Verificou-se que, antes da EC n. 86/2015, a propositura de emendas e a sua aprovação não garantiam que o projeto da LOA, uma vez aprovado e sancionado, fosse implementado. Embora os parlamentares tenham o direito de propor emendas, cabia ao Executivo determinar quais delas seriam executadas, o que provocava uma certa primazia do Poder Executivo em relação ao Legislativo nessa relação. Contudo, isso não significa que os parlamentares não colhiam frutos dessa forma de atuação, já que a eles interessava a propositura e aprovação de suas emendas individuais com o nítido propósito de mautenção de sua base eleitoral e de sua perpetuação no cenário político, ainda que à custa de um subserviente apoio às políticas do governo, traço característico do nosso presidencialismo de coalizão.

Após a aprovação da EC n. 86/2015, não obstante tenha se restringido a margem de discrionariedade do Poder Executivo em relação às emendas parlamentares, o que se observou foi a confirmação da hipótese inicialmente aventada, no sentido de aprofundar as mazelas de nosso sistema político. Ainda que tenha sido conferido ao Poder Legislativo maior autonomia para a proposição de alterações orçamentárias, em busca de um maior equilíbrio entre ambos os Poderes, a tendência é a permanência das práticas clientelistas, corruptas e patrimonialistas que permeiam a nossa realidade política.

Perde-se, assim, a oportunidade de buscar uma maior convergência dos recursos derivados de emendas individuais com as prioridades e as políticas estruturantes préestabelecidas, a fim de que o Poder Legislativo retome o papel que constitucionalment lhe é assegurado. Ao contrário, a alteração realizada apenas confirma o desinteresse dos nossos parlamentares para influenciar de forma efetiva e proveitosa na definição das políticas públicas relevantes, em nome do aperfeiçoamento de uma lógica paroquial, personalista e nefasta aos verdadeiros desígnios da democracia brasileira.

\section{REFERÊNCIAS}


ABRANCHES, Sérgio Hudson de. Presidencialismo de coalizão: o dilema institucional brasileiro. Dados, Rio d Janeiro, v. 31, n.1, p.5-38, 1988.

AMES, Barry. Os entraves da democracia no Brasil. Rio de Janeiro: Fundação Getúlio Vargas, 2003.

BRASIL. Constituição (1988). Constituição da República Federativa do Brasil. Brasília, 5 de outubro de 1988.1 Disponível em: $<$ http://www.planalto.gov.br/ccivil_03/constituicao/constituicao.htm>. Acesso em: 9 jul. 2016.

BRASIL. Constituição (1988). Emenda constitucional n. 86, de 17 de março de 2015. Altera os arts. 165, 166 e 198 da Constituição Federal, para tornar obrigatória a execução da programação orçamentária que especifica. Disponível em: $<$ http://www.planalto.gov.br/ccivil_03/Constituicao/Emendas/Emc/emc86.htm>. Acesso em 09 jul. 2016.

BRASIL. Lei Complementar n. 101, de 04 de maio de 2002. Estabelece normas de finanças públicas voltadas para a responsabilidade na gestão fiscal e dá outras providências. Disponível em: <http://www.planalto.gov.br/ccivil_03/leis/LCP/Lcp101.htm>. Acesso em: 10 jul. 2016.

BRASIL. Lei n. 4.320, de 17 de março de 1964. Estatui Normas Gerais de Direito Financeiro para elaboração e contrôle dos orçamentos e balanços da União, dos Estados, dos Municípios e do Distrito Federal. Disponível em: <http://www.planalto.gov.br/ccivil_03/leis/L4320.htm>. Acesso em: 10 jul. 2016.

BRASIL. Resolução Conjunta ${ }^{\circ}$ 01/2006- CN. Dispõe sobre a Comissão Mista Permanente a que se refere $o \S 1^{\circ}$ do art. 166 da Constituição, bem como a tramitação das matérias a que se refere 0 mesmo artigo. Disponível em: <http://www2.camara.leg.br/legin/fed/rescon/2006/resolucao-1-22-dezembro-2006-548706norma-pl.html>. Acesso em: 10 jul. 2016.

BRASIL. Supremo Tribunal Federal. Voto na Ação Direta de Inconstitucionalide n. 4.663/RO. Relator Ministro Luiz Fux. Disponível em: $<$ http://www.stf.jus.br/arquivo/cms/noticiaNoticiaStf/anexo/adi4663.pdf>. Acesso em: 10 jul. 2016.

BRASIL. Ministério do Planejamento, Orçamento e Gestão, 2015. Orçamento Impositivo Orientações: Procedimentos, Prazos e Responsabilidades. Disponível em: $<$ http://www.orcamentofederal.gov.br/biblioteca/publicacoes_tecnicas/CARTILHA\%20IMP OSITIVO_05_02.pdf>. Acesso em: 10 jul. 2016.

DALLARI, Adilson Abreu. Orçamento impositivo, In: CONTI, José Maurício; SCAFF, Fernando Facury (Coord.). Orçamentos públicos e direito financeiro. São Paulo: Revista dos Tribunais, p. 309-327, 2011,.

DALLAVERDE, Alexsandra Katia. As relações entre os poderes na gestão das finanças públicas. Porto Alegre: Nuria Fabris Editora, 2013. 
FERREIRA, Marcelo Vaz. Orçamento impositivo no Brasil: análise da Proposta de Emenda à Constituição n. 565/2006 e as implicações políticas e econômicas do novo arranjo institucional. Monografia apresentada ao Programa para aprovação no Curso de Especialização em Orçamento Público. Instituto Serzedello Corrêa do Tribunal de Contas da Uniãoo em parceria com o Centro de Formação, Treinamento e Aperfeiçoamento da Câmara dos Deputados, 2007.

LIMONGI, Fernando; FIGUEIREDO, Argelina. Processo Orçamentário e Comportamento Legislativo: Emendas Individuais, Apoio ao Executivo e Programas de Governo. Dados, Rio de Janeiro, v. 48, n. 4, 2005, p. 737 a 776. Disponível em: <http://www.scielo.br/pdf/dados/v48n4/28478.pdf>. Acesso em: 3 set. 2016.

GODOY, Arnaldo Sampaio de Moraes. O tema do orçamento impositivo no ordenamento jurídico brasileiro. Revista da AJURIS, Porto Alegre, v. 41, n. 134, Jun. 2014. Disponível em: < http://www.ajuris.org.br/OJS2/index.php/REVAJURIS/article/view/195/131>. Acesso em 3 set. 2016.

HARADA, Kyoshi. Orçamento impositivo: exame da PEC $\mathbf{n}^{\mathbf{0}}$ 565/06. Revista Jus Navigandi, Teresina, ano 18, n. 3827, 23 dez. 2013. Disponível em: <https://jus.com.br/artigos/26167>. Acesso em: 4 jul. 2016.

MELO, Marcos. Emendas parlamentares. In: AVRITZER, Leonardo; ANASTASIA, Fátima. Reforma política no Brasil. Belo Horizonte: Ed. UFMG, 2006, p. 197-201.

MENDONÇA, Eduardo. Constituição e sociedade: o falso orçamento impositivo. 2016. Disponível em: <http://jota.uol.com.br/constituicao-e-sociedade-o-falso-orcamentoimpositivo>. Acesso em: 8 jul. 2016.

OLIVEIRA, Régis Fernandes. Curso de Direito Financeiro. São Paulo: Revista dos Tribunais, 2007.

PEREIRA, Carlos; MUELLER, Bernardo. Comportamento estratégico em presidencialismo de coalizão: as relações entre Executivo e Legislativo na elaboraçãoo do orçamento brasileiro. Dados, Rio de Janeiro, v. 45, n. 2, p.265-301, 2002.

RENNÓ, Lúcio R. Críticas ao presidencialismo de coalizão no Brasil: processos institucionalmente constritos ou individualmente dirigidos? In: AVRITZER, Leonardo; ANASTASIA, Fátima. Reforma política no Brasil. Belo Horizonte: Ed. UFMG, 2006, p. 259271.

TOLLINI, Helio (2008). Em busca de uma participação efetiva do Congresso no processo de elaboração orçamentária. Brasília, 2008, p. 15. Disponível em: $<$ http://bd.camara.gov.br/bd/handle/bdcamara/1781>. Acesso em: 10 jul.2016.

VOLPE, Ricardo Alberto e CAMBRAIA, Túlio. A experiência do orçamento impositivo na lei de diretrizes orçamentárias para 2014. RBPO, Brasília , v. 5, n. 2, p. 100-131, 2015. 